\title{
Experiences of In-Patients with Skin Cancer in a German University Hospital Setting: A Cross-Sectional Survey
}

This article was published in the following Dove Press journal: Patient Preference and Adherence

\author{
Theresa Steeb $\mathbb{1}^{1,2}$ \\ Anja Wessely (iD) ${ }^{1,2}$ \\ Heike Merkl $^{3}$ \\ Caroline Voskens (iD ${ }^{1,2}$ \\ Michael Erdmann (iD) ${ }^{1,2}$ \\ Lucie Heinzerling ${ }^{1,2}$ \\ Carola Berking (iD) ${ }^{1,2}$ \\ Markus V Heppt (iD) ${ }^{1,2}$ \\ 'Department of Dermatology, University \\ Hospital Erlangen, Friedrich-Alexander- \\ University (FAU) Erlangen-Nuremberg, \\ Erlangen 91054 , Germany; ${ }^{2}$ Comprehensive \\ Cancer Center Erlangen, European \\ Metropolitan Region of Nuremberg, \\ Erlangen, Germany; ${ }^{3}$ University Hospital \\ Erlangen, Friedrich-Alexander-University \\ Erlangen-Nuremberg (FAU), Erlangen \\ 91054, Germany
}

Correspondence: Markus V Heppt Department of Dermatology, University Hospital Erlangen, Friedrich-AlexanderUniversity (FAU) Erlangen-Nuremberg, Ulmenweg 18, Erlangen 91054, Germany Tel +49-9|3I-85-35747

Email markus.heppt@uk-erlangen.de
Purpose: An important measure of hospital quality is the satisfaction of the patients receiving in-patient care. This cross-sectional study aimed to assess skin cancer patients' experiences in a university hospital setting as a measure of quality of cancer care.

Patients and Methods: Questionnaires were mailed to patients with skin cancer after receiving in-patient overnight treatment in the dermatological unit of the university hospital Erlangen (Germany) from 1 September to 30 November 2017. Patients were asked to evaluate their overall experience of this episode of care and to complete the Picker Inpatient Survey questionnaire on specific aspects of their care, such as patient satisfaction regarding contact with staff, need for information, recommendation of the hospital as well as tumor-specific questions. The results were re-coded as problems and reported as frequencies and their percentage.

Results: A total of 103 of 159 questionnaires were returned (64.8\%). All patients rated the treatment and care they had received to be good or very good. Additionally, all patients would recommend our in-patient clinic to their families or friends. The patients most commonly criticized inconsistency of care delivered by the same physician $(29.7 \%, 30 /$ $101)$ and feeling of insufficient involvement in the decision-making processes $(21.1 \%, 20 /$ 95). Besides this, $19.0 \%(11 / 58)$ and $34.6 \%$ (18/52) of patients were not satisfied with physicians and nurses, respectively, appropriately addressing their fears or anxieties. In the cancer-specific questionnaire, the majority of patients were dissatisfied with further support regarding professional and social rehabilitation possibilities $(85.7 \%, 30 / 35)$ and psychooncology $(56.3 \%, 18 / 32)$.

Conclusion: Overall, the majority of patients were satisfied with the in-patient skin cancer treatment. However, physicians and nurses can enhance patient satisfaction by addressing patients' fears and anxieties regarding their disease and treatment. Besides, our results highlight the importance of psycho-oncological support.

Keywords: patient satisfaction, quality improvement, dermatology, hospital evaluation, inpatient experiences, skin cancer

\section{Introduction}

Patient satisfaction is the net result of their experience of health care. ${ }^{1}$ It is a key parameter to measure the quality of care in a hospital; furthermore, it is perceived as equally important as traditional measured outcome parameters like mortality. ${ }^{2-4}$ In the absence of a common definition, measuring patient experience remains challenging and benchmarking is necessary in order to come to meaningful conclusions and comparisons, both intramural and extramural. Despite their different 
meanings, patient experience is often interchangeable with terms such as patient satisfaction, perceptions or preferences. ${ }^{5}$ However, patient experiences are usually perceived as less subjective than patient satisfaction as patients can be satisfied with the health-care system despite having had negative experiences and vice versa. ${ }^{6}$

It is increasingly recognized that patients' perspectives are crucial for quality care, as they provide information on the provider's success in meeting patients' expectations from their own subjective perspective..$^{7-10}$ Regular assessment of patient satisfaction in a hospital-based setting is essential for identifying problems that need to be resolved in order to improve the quality of health services. ${ }^{11}$ Additionally, patient satisfaction might have an influence on whether patients are willing to further recommend the respective hospital or not. ${ }^{1,7}$ Furthermore, higher patient satisfaction with health services has a positive effect on patients' behavioral intentions, such as adherence to the treatment and follow-up appointments, which ultimately leads to better treatment outcomes. ${ }^{1,12}$

It has become common practice for health organizations to measure patient satisfaction and, as a result, various tools have been developed and implemented to measure patient satisfaction. ${ }^{13-15}$ In Germany, hospitals have been legally obliged to provide information about their work in quality reports since $2005 .{ }^{16}$ The quality reports provide an overview of the structures and services of hospitals. Measuring patient satisfaction has therefore become an essential and mandatory part of the quality assurance process. $^{16,17}$

Here, we report the results of the most recent evaluation of the satisfaction of skin cancer patients with in-patient (i.e. overnight) treatment at the department of dermatology of the University Hospital Erlangen. The results will identify specific aspects of the treatment algorithm that are good as well as those that need to be improved in the future to increase patient satisfaction.

\section{Patients and Methods}

\section{Study Design, Setting, and Participants}

This cross-sectional study was conducted as part of the mandatory quality assurance of German hospitals. The University Hospital Erlangen is a tertiary treatment center and teaching hospital of the medical faculty of the Friedrich-Alexander-University (FAU) ErlangenNürnberg. This study was approved by the institutional review board of the University Hospital (UK Erlangen) (approval number 20200812 01).

All patients $\geq 18$ years who had been admitted to the dermatological clinic and who had been discharged from 1 September to 30 November 2017 were eligible for participation. Patients with pre-defined main diagnosis of skin cancer according to ICD-10 were included and deceased patients as well as patients who had been re-admitted during that period of time were excluded in this study. Participation was voluntary and each participant was allowed to participate only once in the survey (crosssectional design). Refusals were documented, no incentives were provided. The cyclical survey was conducted similar to a postal vote. Overall, 157 patients received a questionnaire by mail without personal identification as well as a pre-printed reply card with the patient's address as sender. Both of them were sent back separately together with the statement regarding informed consent, hence, no systematic assignment was traceable. A double reminder system was deployed to ensure a high return rate of the questionnaires.

\section{Survey}

The Picker Patient Experience Questionnaire is a validated and reliable tool to assess in-patient experience. ${ }^{14}$ It has been used to evaluate hospital service quality in many countries. We used the German version of the validated in-patient Picker Patient Experience as well as the add-on for tumor-specific questions. ${ }^{14}$ The questionnaire consisted of 44 items on various aspects of in-patient care, such as patient satisfaction regarding the physician-patient and nurse-patient relationship, information needs, and general impression. In addition, socio-demographic data such as age, health insurance status and gender were obtained. Moreover, participants could add further comments and suggestions for improvement in a free-text field. The items mainly included closed questions and used a 3/4-point Likert scale (graded for example as "yes, always", "yes, sometimes", "never" and "I do'nt need to ask", respectively). All individual questions that measured potential problems were dichotomized as a problem score ("yes, sometimes" and "never"), indicating the presence or absence of a problem. ${ }^{18}$

\section{Data Analysis}

Descriptive statistics was used to describe patient demographics and the results were reported as frequencies 
and their percentage (\%). Microsoft Excel 2010 was used to analyze the data. The open-ended questions were analyzed qualitatively. No sample size calculation was performed due to the explorative design of the survey. Missing data were addressed by indicating the number of participants considered in each analysis. Aggregated dates were provided by BQS Institut für Qualität \& Patientensicherheit GmbH.

\section{Results}

\section{Baseline Characteristics}

Overall, 103 of 159 questionnaires were returned; 31 patients were female and 68 were male $(n=4$ missing) (Table 1). The majority were over 74 years $(45 / 103$, $43.7 \%)$ of age, followed by $65-74$ years $(25 / 103,23.3 \%)$ and 55-64 years $(14 / 103,13.6 \%)$. Seven patients were aged between 36 and 54 years $(6.8 \%)$ and one patient was below 35 years $(1.0 \%)$. The majority rated their general wellbeing as good $(53.4 \%, 55 / 103)$. Nearly $60 \%$ of the patients $(59.2 \%, 61 / 103)$ had public health insurance. Besides, half of the patients stated to be affected by a chronic disease $(46.6 \%, 48 / 103)$ and most of them stated that their chronic disease lasted between 6 months and a year $(39.6 \%, 19 / 48)$.

\section{Dissatisfaction with Physician and Nurse Performance}

The most poorly rated aspect according to the patients was the involvement of several physicians in the treatment algorithm (29.7\%, 30/101; Table 2). Besides, $21.1 \%$ of patients $(20 / 95)$ felt insufficiently involved in the decision-making processes about their disease or treatment. Another $19.0 \%$ of patients $(11 / 58)$ were also unsatisfied with physicians not appropriately addressing their fears or anxieties about their condition or treatment. Additionally, $34.6 \%$ of the patients $(18 / 52)$ were unsatisfied with how the nurses addressed their fears or anxieties. Furthermore, $15.7 \%$ of patients (16/102) criticized that the results of their examination had not been explained to them understandably by the physicians.

\section{General Impression}

Regarding the general impression of the department of dermatology, all patients rated the treatment and care they had received to be good or very good and, additionally, all patients would recommend the department of dermatology to their family or friends (Table 2).
Table I Baseline Characteristics of the Included Patients (\%(N))

\begin{tabular}{|c|c|}
\hline \multicolumn{2}{|l|}{ Gender $(n=103)$} \\
\hline Female & $29.1 \%(31)$ \\
\hline Male & $66.0 \%(68)$ \\
\hline Not specified & $3.9 \%(4)$ \\
\hline \multicolumn{2}{|l|}{ Age $(n=103)$} \\
\hline $18-35$ years & $0.9 \%(I)$ \\
\hline $36-54$ years & $6.8 \%(7)$ \\
\hline $55-64$ years & $13.6 \%(14)$ \\
\hline $65-74$ years & $23.3 \%(24)$ \\
\hline$\geq 74$ years & $43.7 \%(45)$ \\
\hline Not specified & $11.7 \%(12)$ \\
\hline \multicolumn{2}{|l|}{ Health insurance status $(n=103)$} \\
\hline Statutory health insurance & $59.2 \%(6 \mathrm{I})$ \\
\hline Statutory health insurance with private & $15.5 \%(16)$ \\
\hline supplementary insurance & \\
\hline Private health insurance & $13.6 \%(14)$ \\
\hline Private health insurance with aid & $7.8 \%(8)$ \\
\hline Not specified & $3.9 \%(4)$ \\
\hline \multicolumn{2}{|l|}{ Education $(n=103)$} \\
\hline No school-leaving certificate & $0.9 \%(I)$ \\
\hline Primary school/secondary school diploma & $15.5 \%(16)$ \\
\hline $\begin{array}{l}\text { Primary school/secondary school leaving certificate } \\
\text { and completed apprenticeship }\end{array}$ & $34.0 \%(35)$ \\
\hline $\begin{array}{l}\text { Secondary school leaving certificate without } \\
\text { university degree }\end{array}$ & $15.5 \%(16)$ \\
\hline Abitur without university degree & $6.8 \%(7)$ \\
\hline University degree & $21.4 \%(22)$ \\
\hline Not specified & $5.8 \%(6)$ \\
\hline \multicolumn{2}{|l|}{ General wellbeing $(n=103)$} \\
\hline Bad & $2.9 \%(3)$ \\
\hline Mediocre & $23.3 \%(24)$ \\
\hline Good & $53.4 \%(55)$ \\
\hline Very good & $17.5 \%(18)$ \\
\hline Excellent & $0 \%(0)$ \\
\hline Not specified & $2.9 \%(3)$ \\
\hline \multicolumn{2}{|l|}{ Chronic disease (more than 6 months) $(n=103)$} \\
\hline Yes & $46.6 \%(48)$ \\
\hline No & $45.6 \%(47)$ \\
\hline Not specified & $7.8 \%(8)$ \\
\hline \multicolumn{2}{|l|}{ Duration of chronic disease $(n=48)$} \\
\hline 6 months - I year & $39.6 \%(19)$ \\
\hline $\mathrm{I}-3$ years & $16.7 \%(8)$ \\
\hline $3-5$ years & $2.1 \%(1)$ \\
\hline$\geq 5$ years & $29.2 \%(14)$ \\
\hline Not specified & $12.5 \%(6)$ \\
\hline
\end{tabular}

Moreover, $17 \%(17 / 100)$ of the patients stated that complications arose after their discharge from the hospital. 
Table 2 Problems Identified for Every Item of the Picker Patient Experience Questionnaire

\begin{tabular}{|c|c|c|}
\hline Item & $\mathbf{n}$ & $\%(\mathbf{N})$ \\
\hline \multicolumn{3}{|l|}{ Satisfaction with physician performance } \\
\hline $\begin{array}{l}\text { No particular physician was responsible for the } \\
\text { care and took regular care of the patient }\end{array}$ & 101 & $29.7 \%(30)$ \\
\hline $\begin{array}{l}\text { Patient did not receive understandable answers } \\
\text { when asking important questions to a physician }\end{array}$ & 94 & $10.6 \%(10)$ \\
\hline $\begin{array}{l}\text { Physicians did not discuss the condition or } \\
\text { treatment-related fears or anxieties with the patient }\end{array}$ & 58 & $19.0 \%(11)$ \\
\hline No trust in the physician & 103 & $6.8 \%(7)$ \\
\hline $\begin{array}{l}\text { Physicians were unfriendly and not } \\
\text { understanding }\end{array}$ & 103 & $1.0 \%(1)$ \\
\hline $\begin{array}{l}\text { Physicians were not there for the patient when } \\
\text { they were in need }\end{array}$ & 97 & $3.1 \%(3)$ \\
\hline $\begin{array}{l}\text { The results of investigations have not been } \\
\text { explained to the patient in an understandable way }\end{array}$ & 102 & $15.7 \%(16)$ \\
\hline $\begin{array}{l}\text { No sufficient involvement in the decision-making } \\
\text { processes about the treatment }\end{array}$ & 95 & $21.1 \%(20)$ \\
\hline \multicolumn{3}{|l|}{ Satisfaction with performance of nurses } \\
\hline $\begin{array}{l}\text { Patient did not receive understandable answers } \\
\text { when asking important questions to the nurses }\end{array}$ & 88 & $9.1 \%(8)$ \\
\hline $\begin{array}{l}\text { Nurses did not discuss the condition or treatment- } \\
\text { related fears or anxieties with the patient }\end{array}$ & 52 & $34.6 \%(18)$ \\
\hline No trust in the nurses & 102 & $10.8 \%(I I)$ \\
\hline Nurses were unfriendly and not understanding & 103 & $3.9 \%(4)$ \\
\hline No provision of help going to the toilet & 20 & $15.0 \%(3)$ \\
\hline $\begin{array}{l}\text { Unreasonable waiting time after pressing the bell } \\
\text { until receiving required assistance }\end{array}$ & 34 & $5.9 \%(2)$ \\
\hline $\begin{array}{l}\text { Nurses were not there for the patient when } \\
\text { they were in need }\end{array}$ & 93 & $2.2 \%(2)$ \\
\hline \multicolumn{3}{|l|}{ General impression } \\
\hline $\begin{array}{l}\text { No improvement of the complaints that led the } \\
\text { patient to stay in the hospital }\end{array}$ & 69 & $7.2 \%(5)$ \\
\hline $\begin{array}{l}\text { Complications arose after the discharge from } \\
\text { the hospital }\end{array}$ & 100 & $17.0 \%(17)$ \\
\hline No success of the medical treatment & 74 & $2.7 \%(2)$ \\
\hline Insufficient treatment and care received & 101 & $0.0 \%(0)$ \\
\hline $\begin{array}{l}\text { No recommendation of the hospital to family or } \\
\text { friends }\end{array}$ & 101 & $0.0 \%(0)$ \\
\hline
\end{tabular}

\section{Tumor-Specific Dissatisfaction}

Most patients stated their general practitioner to be the caring physician besides those of the skin cancer center, followed by a specialist in private practice (Figure 1, Table $3)$. The majority of patients $(85.7 \%, 30 / 35)$ were dissatisfied with further support, especially with the offer of social services of the tumor center to professional and social rehabilitation possibilities (Table 3). Another 56.3\% (18/

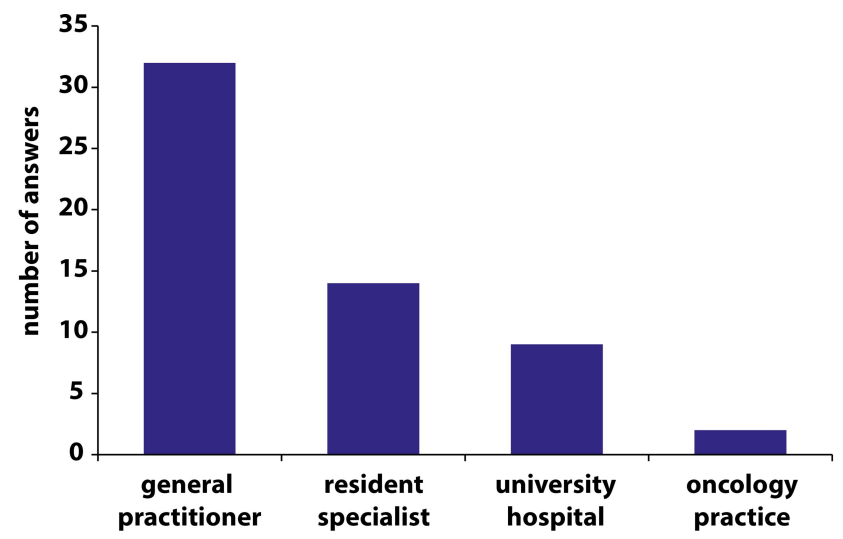

Figure I Bar chart illustrating patients' caring physicians besides the tumor center ( $n=43$; multiple answers possible; not specified: $n=60$ ).

32) criticized that they had not been offered support from the psycho-oncology service after the diagnosis of their cancer condition. Additionally, most patients were dissatisfied with the opportunity to talk to other employees at the tumor center about their disease: $87.5 \%$ (7/8) of patients stated to not have had sufficient opportunity to talk about their illness in peace and quiet with other employees and $72.7 \%(8 / 11)$ voted to have insufficient opportunity to talk to a psycho-oncologist about their disease. Furthermore, $71.4 \%(5 / 7)$ of patients criticized that other employees did not respond appropriately to their fears and concerns regarding their disease, followed by $60.0 \%(6 / 10)$ who criticized the psycho-oncologists for inadequately addressing their fears and anxieties.

Regarding additional information requested by skin cancer patients, the majority responded that they did not need additional information, followed by additional information on scientific progress, nutrition, the treatment itself or the treatment options, the side effects of the treatment and alternative therapies to conventional medicine (Figure 2).

\section{Discussion}

This cross-sectional study provided insights into the satisfaction of skin cancer patients receiving in-patient treatment at a major German skin cancer center in a university hospital-based setting. Overall, the patients in our study were highly satisfied with the treatment and care provided, including the performance by both physicians and nurses. All patients rated the treatment and care they had received to be good or very good and additionally, all patients would recommend the department of dermatology to their family or friends. This highlights that patients' 
Table 3 Additional Problems Identified Among Patients with Tumor Diseases

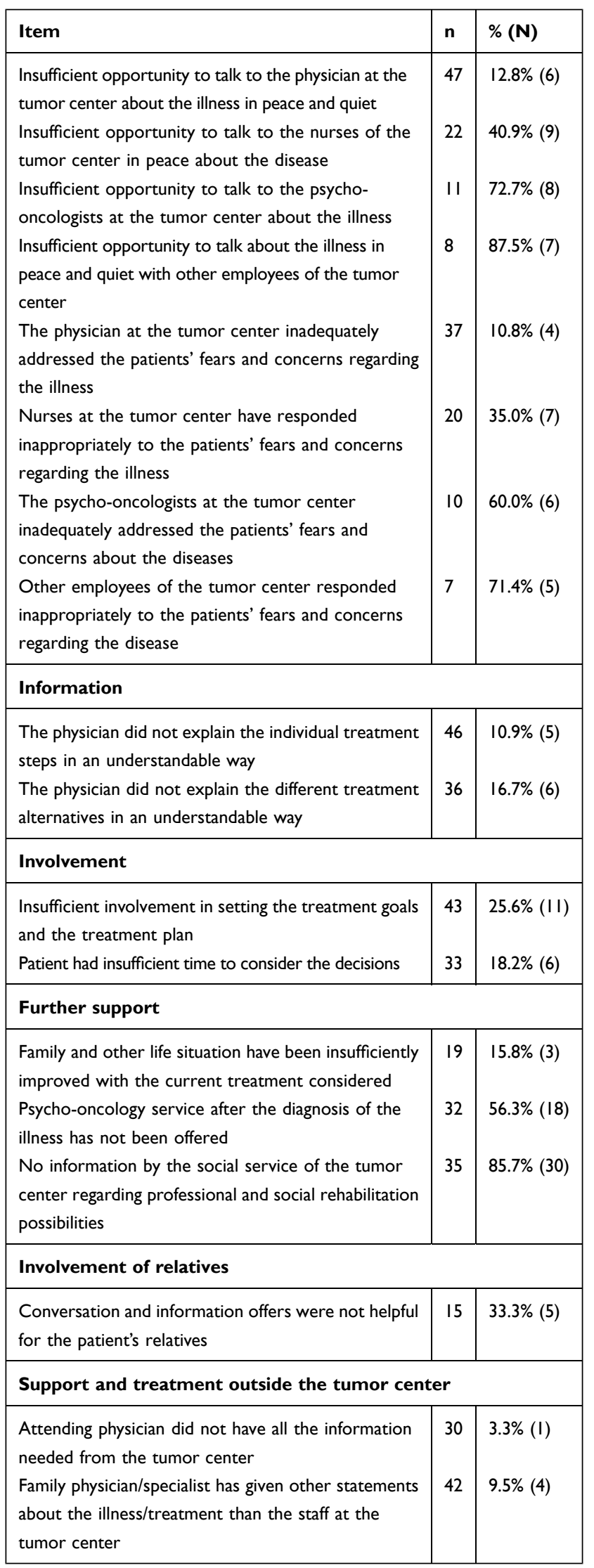

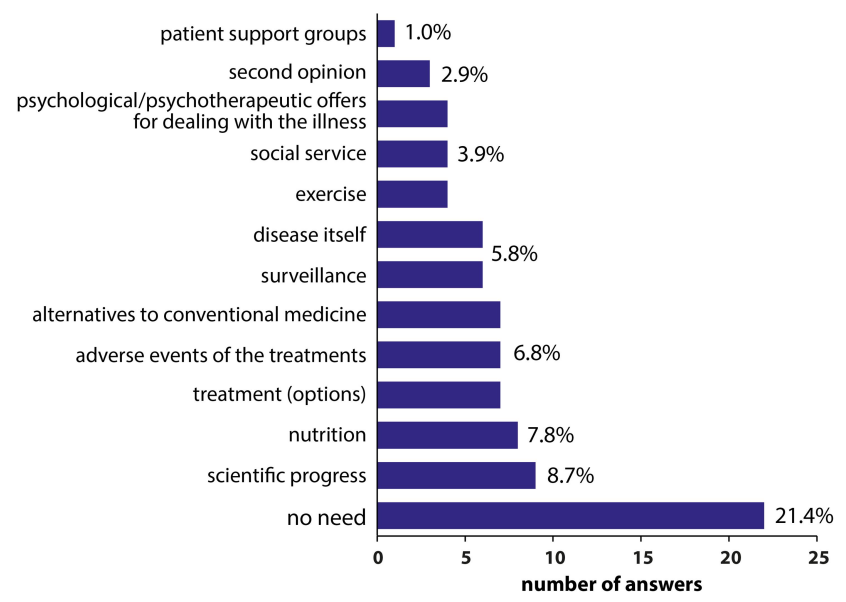

Figure 2 Bar chart showing patients' desire for information in the tumor center ( $n=41$, multiple answers possible; not specified: $n=64$ ).

expectations regarding their in-patient experience at the dermatological department were oftentimes met. These findings are similar to the results of a survey on patient satisfaction in the dermatological unit of the university hospital of Würzburg in Germany, where nearly all of 332 patients (98\%) patients stated that they would like to be treated in the clinic again. ${ }^{19}$ However, comparison is limited as the questionnaires deployed in Würzburg differed from the questionnaire used in our survey. ${ }^{19}$

Inconsistency of care by the same physician, i.e. change of doctor, and the feeling of insufficient involvement in the decision-making processes about the disease or respective treatment were among the most criticized aspects reported by the patients. Shared decision-making has become a crucial and substantial concept in cancer care over the last years. ${ }^{20}$ A questionnaire study among two German skin cancer centers demonstrated that more than $80 \%$ of melanoma patients want to play an active role, i.e. either autonomous or collaborative, in treatment decisions, while $17 \%$ want to fully delegate their decision to the physician. ${ }^{21}$ Thus, shared decision-making has also been adopted as an explicit goal in the German evidenceand consensus-based guideline on the treatment of melanoma. ${ }^{22}$ The reported lack of involvement in decision-making in our study might be explained by the limited time resources of the physicians for consultation or by insufficient knowledge about appropriate decision-aids due to the abundance of different sources such as booklets, videos or internet webpages with varying quality. ${ }^{23-25}$ However, the increasing complexity of new therapies as for example immune checkpoint blockade may be a serious barrier for shared decision-making. 
Nevertheless, patients expect their physicians to advise them about information resources such as the internet or booklets, which they could use in addition to medical consultations, as has been demonstrated in a crosssectional survey of melanoma patients in 27 German skin cancer centers. ${ }^{26}$ In another analysis, the authors also highlighted that younger clinicians tend not to recommend additional sources of information and support in contrast to older clinicians, while non-recommending of decisionaids was irrespective of the clinicians' gender and qualification. $^{27}$ Hence, especially younger dermatooncologists should be encouraged to involve their patients in the decision-making processes about the disease or respective treatment. Besides, counseling with experienced dermato-oncologists about their preferred decision-aids might be a first step towards improved shared decisionmaking.

Surprisingly, many patients were not satisfied with the physicians appropriately addressing their fears or anxieties. This indicates an important need of the patients in this sample regarding the highly sensitive topic of skin cancer. However, especially in terms of short or restricted stays of the patient at the hospital, it is difficult for both the physician as well as the patient to create a substantial relationship. The importance of emotional support was also identified in a survey on patient satisfaction from Italy, ${ }^{28}$ which matches our results as well. As a result, the respective hospital management decided to offer training to improve the communication skills of the staff. ${ }^{28}$

Interestingly, more than half of the patients stated to be dissatisfied with information about the support by a psycho-oncologist, although the structural requirements of a qualified psycho-oncology program are an essential aspect of comprehensive patient care and have been established in certified skin cancer centers such as Erlangen..$^{22,29,30}$ Overall, our findings are in line with the results from a German multicenter, cross-sectional study among 529 melanoma patients where most patients (55\%) felt poorly or not at all informed about psychosocial support as well. ${ }^{31}$ Nevertheless, the sole medical assessment might deviate significantly from the actual patient need and is therefore not always an adequate indicator for the identification of a need for care and information. ${ }^{32}$ Interestingly, nearly all certified skin cancer centers in Germany, Switzerland and Austria reported offering information/counseling, crisis intervention, oneon-one discussions, and palliative/end-of-life care as part of their psycho-oncology program. ${ }^{33}$ Furthermore, the majority of centers in this sample admitted that their psycho-oncology programs primarily focus on inpatients. ${ }^{33}$ However, in addition to the psychosocial burden, the desire for support should be assessed and patients should be provided with access to additional psychosocial care and support. ${ }^{34,35}$ In general, there is an urgent need to raise awareness of psycho-oncology not only in the hospitals but also in private practice, which has been confirmed by a recent survey on psychooncological care in dermatological practices in Germany. $^{36}$

\section{Conclusion}

Overall, the majority of patients were satisfied with their treatment. Ideally, patient care should be provided by oneand-the-same physician, at least during regular working hours. Physicians and nurses can enhance patient satisfaction by addressing patients' fears and anxieties regarding their disease and treatment. Besides, physicians should try to care consistently for the same patients. Additionally, tumor centers should encourage and strengthen patients' contact with psycho-oncologists.

\section{Acknowledgments}

We thank the BQS Institut für Qualität \& Patientensicherheit $\mathrm{GmbH}$ for providing the aggregated data of this survey.

\section{Disclosure}

Lucie Heinzerling reports grants from Novartis, honoraria for advisory board, presentations from Curevac, BMS, MSD, Amgen, Novartis, Roche, Pierre Fabre, Sanofi, and clinical studies for Curevac, BMS, MSD, Amgen, Novartis, Roche, Pierre Fabre, Sanofi, during the conduct of the study. The remaining authors report no potential conflicts of interest in this work.

\section{References}

1. Pascoe GC. Patient satisfaction in primary health care: a literature review and analysis. Eval Program Plann. 1983;6(3-4):185-210. doi:10.1016/0149-7189(83)90002-2

2. Nelson-Wernick E, Currey HS, Taylor PW, Woodbury M, Cantor A. Patient perception of medical care. Health Care Manage Rev. 1981;6 (1):65-72. doi:10.1097/00004010-198124000-00008

3. Guzman PM, Sliepcevich EM, Lacey EP, et al. Tapping patient satisfaction: a strategy for quality assessment. Patient Educ Couns. 1988;12(3):225-233. doi:10.1016/0738-3991(88)90006-7

4. Sack C, Lutkes P, Gunther W, Erbel R, Jockel KH, Holtmann GJ. Challenging the holy grail of hospital accreditation: a cross sectional study of inpatient satisfaction in the field of cardiology. BMC Health Serv Res. 2010;10:120. doi:10.1186/1472-6963-10-120 
5. Ahmed F, Burt J, Roland M. Measuring patient experience: concepts and methods. Patient. 2014;7(3):235-241. doi:10.1007/s40271-0140060-5

6. Salisbury C, Wallace M, Montgomery AA. Patients' experience and satisfaction in primary care: secondary analysis using multilevel modelling. BMJ. 2010;341:c5004. doi:10.1136/bmj.c5004

7. Otani K, Kurz RS, Harris LE. Managing primary care using patient satisfaction measures. J Healthc Manag. 2005;50(5):311-324.

8. Ware JE, Snyder MK, Wright WR, Davies AR. Defining and measuring patient satisfaction with medical care. Eval Program Plann. 1983;6(3-4):247-263. doi:10.1016/0149-7189(83)90005-8

9. Doyle C, Lennox L, Bell D. A systematic review of evidence on the links between patient experience and clinical safety and effectiveness. BMJ Open. 2013;3(1):e001570. doi:10.1136/bmjopen-2012-001570

10. Rathert C, Brandt J, Williams ES. Putting the 'patient' in patient safety: a qualitative study of consumer experiences. Health Expect. 2012;15(3):327-336. doi:10.1111/j.1369-7625.2011.00685.x

11. Ruggeri M, Lasalvia A, Bisoffi G, et al. Satisfaction with mental health services among people with schizophrenia in five European sites: results from the EPSILON study. Schizophr Bull. 2003;29 (2):229-245. doi:10.1093/oxfordjournals.schbul.a007000

12. Sitzia J, Wood N. Patient satisfaction: a review of issues and concepts. Soc Sci Med. 1997;45(12):1829-1843. doi:10.1016/ S0277-9536(97)00128-7

13. Boyer L, Francois P, Doutre E, Weil G, Labarere J. Perception and use of the results of patient satisfaction surveys by care providers in a French teaching hospital. Int J Qual Health Care. 2006;18 (5):359-364. doi:10.1093/intqhe/mzl029

14. Jenkinson C, Coulter A, Bruster S. The picker patient experience questionnaire: development and validation using data from in-patient surveys in five countries. Int $J$ Qual Health Care. 2002;14 (5):353-358. doi:10.1093/intqhe/14.5.353

15. Al-Abri R, Al-Balushi A. Patient satisfaction survey as a tool towards quality improvement. Oman Med J. 2014;29(1):3-7. doi:10.5001/ omj.2014.02

16. Gemeinsamer Bundesausschuss. Qualitätsberichte der Krankenhäuser. Available from: https://www.g-ba.de/themen/quali taetssicherung/datenerhebung-zur-qualitaetssicherung/datenerhe bung-qualitaetsbericht/. Accessed August 3, 2020.

17. Schoenfelder T, Klewer J, Kugler J. Determinants of patient satisfaction: a study among 39 hospitals in an in-patient setting in Germany. Int J Qual Health Care. 2011;23(5):503-509. doi:10.1093/intqhe/ mzr038

18. Jenkinson C, Coulter A, Bruster S, Richards N, Chandola T. Patients' experiences and satisfaction with health care: results of a questionnaire study of specific aspects of care. Qual Saf Health Care. 2002;11(4):335-339. doi:10.1136/qhc.11.4.335

19. Quist SR, Dieckmann-Stocklein R, Brocker EB, Weyandt GH. Determinants of patient satisfaction in a university clinic of dermatology as a parameter for patient orientation in quality management. J Dtsch Dermatol Ges. 2007;5(7):598-604. doi:10.1111/j.16100387.2007.00000.x

20. Harter M, Muller H, Dirmaier J, Donner-Banzhoff N, Bieber C, Eich W. Patient participation and shared decision making in Germany - history, agents and current transfer to practice. Z Evid Fortbild Qual Gesundhwes. 2011;105(4):263-270. doi:10.1016/j. zefq.2011.04.002
21. Albrecht KJ, Nashan D, Meiss F, Bengel J, Reuter K. Shared decision making in dermato-oncology: preference for involvement of melanoma patients. Melanoma Res. 2014;24(1):68-74. doi:10.1097/ CMR.0000000000000030

22. Pflugfelder A, Kochs C, Blum A, et al. Malignant melanoma S3guideline "diagnosis, therapy and follow-up of melanoma". J Dtsch Dermatol Ges. 2013;11(Suppl 6):1-116, 111-126.

23. Brutting J, Reinhardt L, Bergmann M, et al. Quality, readability, and understandability of German booklets addressing melanoma patients. J Cancer Educ. 2019;34(4):760-767. doi:10.1007/s13187-018-1369-x

24. Brutting J, Steeb T, Reinhardt L, Berking C, Meier F. Exploring the most visible german websites on melanoma immunotherapy: a web-based analysis. JMIR Cancer. 2018;4(2):e10676. doi:10.2196/ 10676

25. Steeb T, Reinhardt L, Gorgmayr C, et al. German YouTube videos as a source of information on cutaneous melanoma: a critical appraisal. J Eur Acad Dermatol Venereol. 2020;34. doi:10.1111/jdv.16510

26. Brutting J, Bergmann M, Garzarolli M, et al. Information-seeking and use of information resources among melanoma patients of German skin cancer centers. J Dtsch Dermatol Ges. 2018;16 (9):1093-1101. doi:10.1111/ddg. 13630

27. Brutting J, Bergmann M, Schadendorf D, et al. Sources of information and support for melanoma patients: differences between patients' and clinicians' preferences. J Dtsch Dermatol Ges. 2019;17 (6):652-654. doi:10.1111/ddg.13831

28. Tabolli S, Molino N, Renzi C, Abeni D, Picardi A, Puddu P. Satisfaction with health care among dermatological inpatients. Eur J Dermatol. 2003;13(2):177-182.

29. Reuter K. Psychooncology: utility, principles and therapeutic options. Psychother Psychosom Med Psychol. 2010;60(12):486-497. doi:10.1055/s-0030-1265937

30. Beutel ME, Blettner M, Fischbeck S, Loquay C, Werner A, Marian H. Psycho-oncological aspects of malignant melanoma. A systematic review from 1990-2008. Hautarzt. 2009;60 (9):727-733. doi:10.1007/s00105-009-1814-1

31. Brutting J, Bergmann M, Garzarolli M, et al. Unmet information needs of patients with melanoma in Germany. Melanoma Res. 2019;29(2):196-204. doi:10.1097/CMR.0000000000000464

32. Nolte S, van der Mei SH, Strehl-Schwarz K, et al. Comparison of patient-reported need of psycho-oncologic support and the doctor's perspective: how do they relate to disease severity in melanoma patients? Psychooncology. 2016;25(11):1271-1277. doi:10.1002/ pon. 4050

33. Meiss F, Loquai C, Weis J, Giesler JM, Reuter K, Nashan D. Psychooncological care of melanoma patients in certified skin cancer centers. J Dtsch Dermatol Ges. 2018;16(5):576-582.

34. Buchhold B, Arnold A, Lutze S, et al. Psychosocial distress and desire for support among inpatients with skin cancer. $J$ Dtsch Dermatol Ges. 2017;15(8):791-799.

35. Buchhold B, Lutze S, Arnold A, et al. Psychosocial distress and desire for support among skin cancer patients - impact of treatment setting. J Dtsch Dermatol Ges. 2018;16(7):861-871.

36. Meiss F, Reuter K, Muller K, Augustin M, Schafer I, Nashan D. Psycho-oncology in dermatological practice: evaluation of need and care structures. Hautarzt. 2019;70(4):283-289. doi:10.1007/s00105018-4350-z 


\section{Publish your work in this journal}

Patient Preference and Adherence is an international, peer-reviewed, open access journal that focusing on the growing importance of patient preference and adherence throughout the therapeutic continuum. Patient satisfaction, acceptability, quality of life, compliance, persistence and their role in developing new therapeutic modalities and compounds to optimize clinical outcomes for existing disease states are major areas of interest for the journal. This journal has been accepted for indexing on PubMed Central. The manuscript management system is completely online and includes a very quick and fair peer-review system, which is all easy to use. Visit http:// www.dovepress.com/testimonials.php to read real quotes from published authors. 